\title{
Effects of dexamethasone, diclofenac, or placebo on the inflammatory response after cataract surgery
}

\section{C-G Laurell, C Zetterström}

Br J Ophthalmol 2002;86:1380-1384

See end of article for authors' affiliations

Correspondence to: C G Laurell, St Erik's Eye Hospital, SE-1 1282 Stockholm, Sweden; cgl@sankterik.se

Accepted for publication 2 July 2002

\begin{abstract}
Aim: To compare the inflammatory response after phacoemulsification and intraocular lens (IOL) implantation using postoperative treatment with dexamethasone, diclofenac, or placebo.

Methods: A prospective, randomised, controlled double masked study including 180 patients enrolled for cataract surgery. The patients were 64-85 years old and had no eye disease other than cataract. After phacoemulsification and IOL implantation the patients were randomised to topical treatment with dexamethasone phosphate $0.1 \%$ (group I), diclofenac sodium $0.1 \%$ (group II), or placebo (saline $0.9 \%$ ) (group III). The drops were administered four times daily during the first week and twice daily during the second, third, and fourth weeks. The inflammatory reaction in the anterior chamber was measured with laser flare photometry preoperatively and 1, 3, and 8 days, 2 and 4 weeks, 2 and 6 months, and 1, 2, and 4 years postoperatively. Inflammatory symptoms were registered. Biomicroscopy and visual acuity determinations were performed. The rate of $\mathrm{Nd}$ :YAG laser posterior capsulotomies after 2 and 4 years was determined.

Results: After 3 and 8 days ( $<<0.0001), 2$ weeks $(p<0.0001)$, and 1 month ( $p=0.0013$ ) median flare was highest in group III. There were no significant differences between group I and II. Inflammatory symptoms and striate keratopathy were more common in group III.

Conclusion: Dexamethasone and diclofenac were equally effective in reducing postoperative inflammation after phacoemulsification and IOL implantation in eyes with no other disease than cataract. Both substances were more effective than placebo.
\end{abstract}

$\mathrm{n}$ recent years the operative technique in cataract surgery has improved and the operation has become less traumatic to the eye. As a result there is less postoperative inflammatory reaction and less breakdown of the blood-aqueous barrier (BAB). ${ }^{1-4}$ Refined surgical techniques as well as more biocompatible intraocular lenses (IOL) have contributed to this development.

Topical corticosteroids are commonly used as a routine treatment during several weeks postoperatively in order to reduce the inflammatory reaction. However, the adverse effects of steroids are well known and include elevation of intraocular pressure, inhibition of wound healing, and facilitation of infections. ${ }^{6}$ As an alternative treatment nonsteroidal anti-inflammatory drugs (NSAIDs) such as diclofenac have been tried and also found to be efficient in reducing $\mathrm{BAB}$ breakdown. ${ }^{7}$

In this study, we report the results of a prospective, randomised, controlled double masked trial comparing the inflammatory response after endocapsular phacoemulsification and heparin surface modified (HSM) IOL implantation using topical treatment with dexamethasone phosphate $0.1 \%$, diclofenac sodium $0.1 \%$ or placebo drops during 4 weeks postoperatively. The main outcome measure was objective evaluation of inflammatory response with laser flare photometry.

\section{PATIENTS AND METHODS}

The study was approved by the local human experimentation ethics committee and informed consent was obtained from all patients. In all, 180 patients, 64-85 years of age with no other known eye disease, enrolled for cataract surgery, and were randomly allocated to postoperative treatment with dexamethasone phosphate $0.1 \%$ (group I), diclofenac sodium $0.1 \%$ (group II), or saline $0.9 \%$ (group III). The trial was a randomised, double masked, single centre study including 60 patients in each of the three treatment groups. The exclusion criteria were pseudoexfoliation syndrome, small pupils $(<5$ $\mathrm{mm}$ after pharmacological dilatation), dark brown iris, glaucoma, uveitis, diabetes, treatment with topical medications, or anti-inflammatory drugs.${ }^{89}$ There were no significant maculopathies. In group I the male to female ratio was 22:38, in group II it was 20:40, and in group III 19:41. Median age was 75 years (range 64-85) in group I, 74 years (64-84) in group II, and 76 years $(64-84)$ in group III. Median flare preoperatively was 5.0 photons/ms in group I, 4.9 photons $/ \mathrm{ms}$ in group II, and 5.1 photons $/ \mathrm{ms}$ in group III. There were no significant differences between the groups at baseline.

All operations were performed by the same surgeon (CGL). Surgery was performed in a standardised way. The pupil was dilated with a combination of $0.75 \%$ cyclopentolate hydrochloride (Cyclogyl) and 2.5\% phenylephrine hydrochloride (Neosynephrine) drops. Gentamicin drops 0.3\% (Gensumycin) were given four times before surgery. The conjunctival sac was rinsed with $0.05 \%$ chlorhexidine solution. No antiinflammatory drugs were given before surgery. Anaesthesia was administered using $1 \%$ tetracaine hydrochloride (Tetracain) drops followed by a sub-Tenon irrigation of about 1.5 $\mathrm{ml}$ of an equal mixture of bupivacaine $5 \mathrm{mg} / \mathrm{ml}$ (Marcain) and ligoocaine (lidocaine) $20 \mathrm{mg} / \mathrm{ml}$ with epinephrine $12.5 \mu \mathrm{g} / \mathrm{ml}$ (Xylocaine adrenaline) in the lower nasal quadrant. A $3.2 \mathrm{~mm}$ wide scleral tunnel incision was performed between 11 and 12 o'clock, continuing about $1.5 \mathrm{~mm}$ into clear cornea to create a self sealing incision. No cautery was used. Sodium hyaluronate ( $1 \%$ Healon) was injected and a continuous circular capsulorhexis with about $5 \mathrm{~mm}$ diameter was made. After hydrodissection, bimanual phacoemulsification was done using the cracking technique. ${ }^{10}$ The irrigation fluid was a balanced salt solution (BSS AMO Endosol) with $0.3 \mathrm{mg}$ of epinephrine per $500 \mathrm{ml}$ BSS. After cortex aspiration Healon was injected and the incision was enlarged to $5.2 \mathrm{~mm}$. A heparin surface modified poly(methylmethacrylate) (PMMA) IOL with a $5.0 \mathrm{~mm}$ optic and an overall diameter of $12.0 \mathrm{~mm}$ was implanted into 
Table 1 Laser flare values (photons $/ \mathrm{ms}$ ) in the three study groups preoperatively and during 4 years postoperatively (median and range). During the first postoperative month median flare was significantly higher in the placebo group (Kruskal-Wallis ANOVA). The flare value in the placebo group rose until 8 days after surgery and then it fell continuously, indicating a spontaneous regression of the BAB damage

\begin{tabular}{|c|c|c|c|c|c|c|c|}
\hline & Dexamethasone & (No) & Diclofenac & (No) & Placebo & (No) & $p$ Value \\
\hline Preop & $5.0(0.5-15.0)$ & 60 & $4.9(2.1-17.4)$ & 60 & $5.1(2.3-18.3)$ & 60 & \\
\hline 1 day & $12.1(0.8-71.2)$ & 60 & $12.4(0.3-89.3)$ & 60 & $13.3(1.2-52.6)$ & 60 & 0.83 \\
\hline 3 days & $10.8(2.4-63.4)$ & 59 & $10.8(2.4-46.7)$ & 60 & $24.3(2.7-145.1)$ & 60 & $<0.0001$ \\
\hline 8 days & $8.6(3.0-64.4)$ & 59 & $7.9(2.7-38.4)$ & 59 & 27.5 (4.0-156.0) & 58 & $<0.0001$ \\
\hline 2 weeks & $7.6(2.7-24.8)$ & 58 & $7.3(1.5-19.0)$ & 59 & $14.3(3.2-67.5)$ & 54 & $<0.0001$ \\
\hline 1 month & $6.0(1.5-15.0)$ & 60 & $7.0(2.6-18.7)$ & 56 & $9.1(2.8-34.2)$ & 55 & 0.0013 \\
\hline 2 months & $6.6(2.8-18.9)$ & 56 & $6.3(2.2-15.8)$ & 54 & $6.1(0.9-20.8)$ & 55 & 0.35 \\
\hline 6 months & $5.9(2.6-12.4)$ & 55 & $5.4(1.8-18.3)$ & 56 & $5.4(0.5-14.9)$ & 50 & 0.23 \\
\hline 1 year & $6.2(3.6-21.1)$ & 53 & $5.8(2.8-20.8)$ & 56 & $5.7(1.7-12.8)$ & 50 & 0.17 \\
\hline 2 years & $7.2(3.6-19.8)$ & 46 & $6.6(2.9-21.8)$ & 50 & $6.1(3.7-22.7)$ & 44 & 0.16 \\
\hline 4 years & $7.1(4.2-16.8)$ & 35 & $6.4(4.4-21.4)$ & 29 & $6.2(3.9-19.3)$ & 36 & 0.43 \\
\hline
\end{tabular}

the capsular bag (one piece PMMA, 809C, Pharmacia and Upjohn). Healon was aspirated and BSS was injected into the anterior chamber. No suture was used. No medications were given at the end of the operation.

Surgery was uncomplicated in all cases. There were no statistically significant differences between the groups regarding operation time, phacoemulsification time, or phacoemulsification energy. In group I median flare rose from 5.0 photons/ms before surgery to 12.1 photons/ms on the first postoperative day. In group II the flare increased from 4.9 photons $/ \mathrm{ms}$ to 12.4 photons/ms, and in group III from 5.1 photons/ms to 13.3 photons $/ \mathrm{ms}$. The differences between the groups were not significant.

The study solution was administered by the patients four times daily during the first week and twice daily during the second, third, and fourth weeks. At day 1 laser flare photometry (Kowa 500) was performed before the study treatment was given. The flare measurements were performed about 30 minutes after dilatation of the pupil at 1,3 , and 8 days, 2 and 4 weeks, 2 and 6 months, and 1, 2, and 4 years postoperatively. The flare value for each patient was averaged from 10 measurements. If an extreme value was found the highest and lowest measurements were eliminated before calculation. The patient was excluded if the coefficient of variation exceeded $35 \%$.

There were no significant differences in pupil size between the groups. Eyes treated with Nd:YAG laser posterior capsulotomy were not included.

The presence of inflammatory symptoms (ciliary flush, pain, and/or photophobia) was registered. At all observation times, except after 3 days and 2 weeks, biomicroscopy was performed in all patients, as well as visual acuity and intraocular pressure (IOP) determinations. Patients were withdrawn from the study if a clinically unacceptable inflammation occurred. This implied a symptomatic inflammation, or more than a slight ciliary injection or aqueous flare.

After 2 and 4 years the rate of Nd:YAG laser posterior capsulotomies in each group was determined.

\section{Assignment}

The patients were randomly allocated to three equal sized groups $(n=60)$. Randomisation was done by a computer in blocks of six patients (randomly permuted blocks, SAS/PLAN procedure). On the first day after surgery, the patients received three coded bottles containing one of the treatment solutions.

\section{Masking}

All bottles were white and non-transparent. They were delivered from the pharmacy with identical labels except for the randomisation number. There was a coding envelope for each number.

\section{Statistics}

The sample size was determined from laser flare photometry data collected by the authors in a previous study. ${ }^{2}$ Using this information, a $5 \%$ significance level and $80 \%$ power, the number of patients needed in each treatment group was 56 to detect a 20\% difference between the groups. The KruskalWallis ANOVA with correction for multiple comparisons was used to detect differences in laser flare between the groups at different time points. Relations between categorical variables were analysed with the $\chi^{2}$ test. The Spearman rank correlation coefficient was used as a measure of correlation. Pupil diameters were analysed with the median test. The calculations were made by computer analysis using Statistica 5.0 (StatSoft).

\section{RESULTS}

\section{Inflammatory response: laser flare photometry}

On the first postoperative day there were no significant differences between the groups. At 3 and 8 days, 2 weeks, and 1 month the flare values were significantly lower in group I (dexamethasone) and group II (diclofenac) compared to group III (placebo) (Table 1). Subsequently, no significant differences were found between the groups. There were no significant differences between groups I and II at any observation time.

The change of the flare from the preoperative measurement to day 1 after surgery was not correlated with the total phacoemulsification energy used (Spearman $R=0.007, \mathrm{p}=$ $0.93, \mathrm{n}=180)$ (Fig 1).

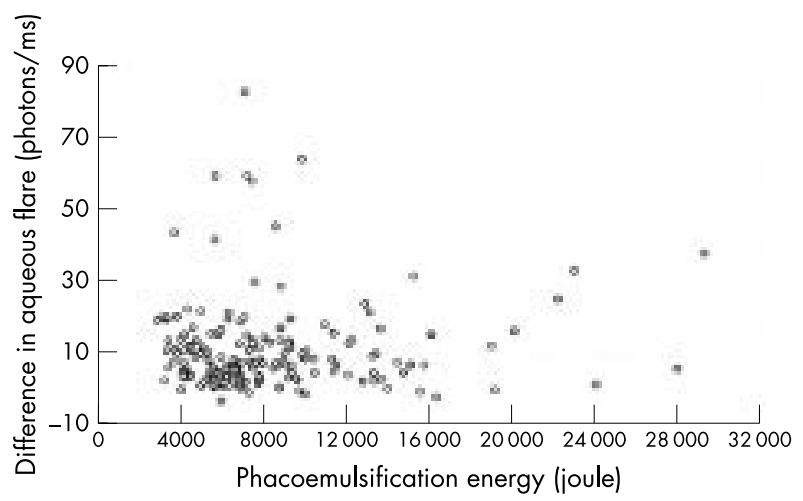

Figure 1 The difference in flare (photons/ms) between the preoperative examination and the first day after surgery was not significantly correlated with the total phacoemulsification energy used during the operation (Spearman $R=0.007, \mathrm{p}=0.93, \mathrm{n}=$ 180). 
Table 2 Rate of patients with inflammatory symptoms (ciliary flush, pain, photophobia) during the first postoperative month. Three and 8 days after surgery the difference between group III (placebo) and the other groups was statistically significant $(p<0.001)\left(\chi^{2}\right.$ test)

\begin{tabular}{lllll}
\hline & 3 days & 8 days & 2 weeks & 1 month \\
\hline Group I & $0 / 60$ & $1 / 60$ & $0 / 59$ & $0 / 59$ \\
Group II & $0 / 60$ & $2 / 59$ & $0 / 59$ & $0 / 55$ \\
Group III & $11 / 60$ & $18 / 59$ & $2 / 59$ & $2 / 55$ \\
\hline
\end{tabular}

There was no general consensual inflammatory response in the unoperated eye.

During the first month after the operation six patients were withdrawn from the study because of inflammatory reactions (see below). Three patients dropped out of the study because of intervening general diseases. A coefficient of variation exceeding $35 \%$ was measured in a few patients during the first 2 months ( $\leqslant$ three patients at each observation time), equally distributed between the groups. At the last three observation times some patients were not available for follow up.

\section{Inflammatory response: clinical outcome \\ Inflammatory symptoms}

In group III inflammatory symtoms were found in 11 of 60 patients $(18.3 \%)$ at day 3 and in 18 of 59 patients $(30.5 \%)$ at day 8. Median flare was higher in these eyes than in the rest of the group, 40.4 (range 8.7-124.5) and 53.0 (9.7-156.0) photons/ms, respectively. Comparing group III to the other groups, the rate of patients with inflammatory symtoms was greater in group III at day $3(\mathrm{p}<0.001)$ and day $8(\mathrm{p}<0.001)$ but not at 2 weeks (Table 2 ). Subsequently all eyes were quiet.

Thus at 2 weeks and subsequently, clinical outcome was similar in group III and the other groups. No significant differences were found between group I and II at any observation time.

\section{Withdrawals due to inflammatory reactions}

No patient in group I was withdrawn from the study. One patient in group II experienced an uveitis with hypopyon 6 days after surgery and was withdrawn from the study. Samples from the anterior chamber and the vitreous were culture negative. The eye improved promptly after treatment with steroids and intravitreal and subconjunctival antibiotics. Visual acuity was 20/20 1 month postoperatively.

During the first 2 weeks after surgery anti-inflammatory treatment was added in four of the 60 eyes in group III because of an clinically unacceptable inflammatory reaction. These four eyes had a ciliary flush and a moderate flare at slit lamp examination and the patients complained of pain. Keratic precipitates were found in two cases. The flare values
Table 4 Rate of patients with striate keratopathy (one or more MD folds) postoperatively. On the first day after surgery there were no significant differences between the groups. At day 8 there were significantly more patients with MD folds in the placebo group (group III) than in the other groups $(p=0.01)\left(\chi^{2}\right.$ test)

\begin{tabular}{lll}
\hline & 1 day & 8 days \\
\hline Group I & $13.3 \%$ & $3.3 \%$ \\
Group II & $(8 / 60)$ & $(2 / 60)$ \\
& $23.3 \%$ & $3.4 \%$ \\
Group III & $(14 / 60)$ & $(2 / 59)$ \\
& $15.0 \%$ & $13.6 \%$ \\
& $(9 / 60)$ & $(8 / 59)$ \\
\hline
\end{tabular}

in these four patients were 27.6, 34.7, 37.6, and 124.5 photons/ms. There was a rapid improvement in all four cases after treatment with topical dexamethasone.

After 1 month a patient in group III had developed a maculopathy with dot haemorrhages causing a decrease of visual acuity. After anti-inflammatory treatment visual acuity was 20/30.

\section{Visual acuity}

There were no significant differences in visual acuity between the groups comparing the number of patients achieving the prospectively defined visual acuity limit of 20/25 except 8 days postoperatively, when visual acuity was significantly lower in group III than in group I $(\mathrm{p}<0.05)$ (Table 3$)$.

\section{Cornea}

Regarding the rate of striate keratopathy (one or more MD folds found in the upper and/or central cornea) there were no significant differences between the groups at day l. However, at day 8 striate keratopathy was more frequent in group III than in the other groups $(\mathrm{p}=0.01)$ (Table 4$)$. Subsequently no corneal reactions were found. No epithelial complications occurred in any of the groups.

\section{Intraocular pressure}

At day 1 there were no significant IOP differences between the groups. After 8 days median IOP was significantly higher in group I ( $16 \mathrm{~mm} \mathrm{Hg})$ than in group III $(13 \mathrm{~mm} \mathrm{Hg})(\mathrm{p}<0.05)$, and at 1 month it was slightly higher in group I ( $15 \mathrm{~mm} \mathrm{Hg}$ ) than in group II ( $14 \mathrm{~mm} \mathrm{Hg})(\mathrm{p}<0.05)$. At the other observation times no significant IOP differences were found. No steroid IOP responder (IOP rise $\geqslant 10 \mathrm{~mm} \mathrm{Hg}$ ) was found.

\section{Capsulotomy rate}

The rate of Nd:YAG laser posterior capsulotomies was equal in the three groups after 2 years. After 4 years it was significantly lower in group III than in group II $(\mathrm{p}<0.05)$ (Table 5$)$.

\begin{tabular}{|c|c|c|c|c|c|c|c|c|}
\hline & 1 day & 8 days & 1 month & 2 months & 6 months & 1 year & 2 years & 4 years \\
\hline Group I & $\begin{array}{l}65.0 \% \\
(39 / 60)\end{array}$ & $\begin{array}{l}81.7 \% \\
(49 / 60)\end{array}$ & $\begin{array}{l}89.8 \% \\
(53 / 59)\end{array}$ & $\begin{array}{l}91.2 \% \\
(52 / 57)\end{array}$ & $\begin{array}{l}91.2 \% \\
(52 / 57)\end{array}$ & $\begin{array}{l}94.4 \% \\
(51 / 54)\end{array}$ & $\begin{array}{l}77.4 \% \\
(41 / 53)\end{array}$ & $\begin{array}{l}68.5 \% \\
(37 / 54)\end{array}$ \\
\hline Group II & $\begin{array}{l}63.3 \% \\
(38 / 60)\end{array}$ & $\begin{array}{l}76.3 \% \\
(45 / 59)\end{array}$ & $\begin{array}{l}83.6 \% \\
(46 / 55)\end{array}$ & $\begin{array}{l}88.9 \% \\
(48 / 54)\end{array}$ & $\begin{array}{l}83.9 \% \\
(47 / 56)\end{array}$ & $\begin{array}{l}82.1 \% \\
(46 / 56)\end{array}$ & $\begin{array}{l}73.7 \% \\
(42 / 57)\end{array}$ & $\begin{array}{l}68.6 \% \\
(35 / 51)\end{array}$ \\
\hline Group III & $\begin{array}{l}60.0 \% \\
(36 / 60)\end{array}$ & $\begin{array}{l}62.7 \% \\
(37 / 59)\end{array}$ & $\begin{array}{l}78.2 \% \\
(43 / 55)\end{array}$ & $\begin{array}{l}92.7 \% \\
(51 / 55)\end{array}$ & $\begin{array}{l}88.7 \% \\
(47 / 53)\end{array}$ & $\begin{array}{l}90.2 \% \\
(46 / 51)\end{array}$ & $\begin{array}{l}89.8 \% \\
(44 / 49)\end{array}$ & $\begin{array}{l}75.5 \% \\
(37 / 49)\end{array}$ \\
\hline
\end{tabular}


Table 5 Rate of $\mathrm{Nd}: \mathrm{YAG}$ laser posterior capsulotomies 2 and 4 years postoperatively. After 4 years there were signifcantly more capsulotomies performed in group II (diclofenac) than in group III (placebo) $(p<0.05)\left(\chi^{2}\right.$ test)

\begin{tabular}{lll}
\hline & 2 years & 4 years \\
\hline Group I & $17.1 \%$ & $47.2 \%$ \\
Group II & $18.2 \%$ & $62.7 \%$ \\
Group III & $15.0 \%$ & $31.9 \%$ \\
\hline
\end{tabular}

\section{DISCUSSION}

Previously a greater need for anti-inflammatory treatment after ECCE than after intracapsular cataract extraction was suggested. ${ }^{11}$ An explanation might be induction of inflammation by remaining lens epithelial cells in the capsular bag. ${ }^{12}{ }^{13}$ Later phacoemulsification has been shown to induce less inflammation and BAB breakdown than ECCE. ${ }^{1-4}$ Interestingly, in this study we found no significant correlation between the postoperative inflammatory reaction and the amount of phacoemulsification energy used during surgery (Fig l).

Because of the improvements in surgical technique and the reduction of $\mathrm{BAB}$ damage the actual need for antiinflammatory therapy after modern cataract surgery has been questioned. ${ }^{14}$ It has been only in the past several years that randomised studies including placebo have been performed..$^{15}{ }^{16}$ In the present trial we compare placebo drops to treatment with dexamethasone phosphate $0.1 \%$ or diclofenac sodium $0.1 \%$ drops after phacoemulsification and implantation of HSM IOL, an IOL that has been shown to induce a low inflammatory response. ${ }^{5}$

Whereas steroids interfere with the inflammatory response in a variety of ways, one of which is the inhibition of arachidonic acid synthesis, NSAIDs decrease inflammation specifically by inhibition of the activity of cyclo-oxygenase, thus decreasing the production of prostaglandins from arachidonic acid. ${ }^{17}$ Unlike other NSAIDs, however, diclofenac indirectly modulates also the lipoxygenase pathway in the arachidonic acid cascade. ${ }^{18}$ This dual mechanism of action of diclofenac may make it comparable in anti-inflammatory activity to the corticosteroids. The results of the present study are in agreement with this presumption, since no significant difference in inflammatory reaction was found between group I (dexamethasone) and group II (diclofenac) at any observation time.

In group III (placebo) median flare in eyes with inflammatory symptoms was higher than in the group as a whole, confirming that an elevated laser flare meter value was pertinent to a clinically significant inflammation. We found that a higher rate of striate keratopathy was associated with a higher flare, suggesting that anti-inflammatory treatment might reduce corneal damage or at least accelerate corneal healing after surgery. The higher flare and particularly the higher rate of MD folds in group III probably explain the lower visual acuity 8 days after surgery (Tables 3 and 4 ).

Only five of the 60 eyes receiving placebo needed rescue treatment, which suggests that most patients could manage without postoperative anti-inflammatory treatment. After less than 2 weeks a spontaneous $\mathrm{BAB}$ recovery started in the absence of anti-inflammatory therapy, indicated by the fall in laser flare values between 8 days and 2 weeks in the placebo group (Table 1). The fact that so many patients needed no additional treatment may be surprising to many surgeons. Indeed, it could be discussed to delay instituting treatment, giving it only to those patients exhibiting symptomatic or clinically unacceptable inflammation at 1 week. Given the cost of medications, one might conclude that no initial treatment would be a more cost effective approach for patients with otherwise normal eyes. However, since significantly more inflammatory symptoms were found in the placebo group during the first week (Table 2), omission of postoperative anti-inflammatory therapy would surely lead to a number of unscheduled visits. It should be noted also, that most of our patients have a blue, light brown, or mixed colour iris, and that we did not include eyes with a dark brown iris, which are prone to more postoperative inflammation. In patients with diabetes, glaucoma, or pseudoexfoliations, who are considered to have a pathological $\mathrm{BAB}$, the need for postoperative treatment should be even greater. The results indicate, however, that there is no cause for alarm if non-symptomatic patients should neglect taking their drops.

It has been proposed that inflammatory mediators might contribute to the development of after-cataract. ${ }^{19}$ Other authors have found a lack of correlation between inflammation and after-cataract formation. ${ }^{20}$ In the present study the rate of Nd:YAG laser posterior capsulotomies was low in the placebo group after 4 years (Table 5), although this group experienced a higher inflammatory response during the first postoperative month. However, capsulotomy rate is a less accurate measure of the development of after-cataract. We therefore intend to evaluate posterior capsular opacification using retroillumination images taken with a Scheimpflug camera.

No typical steroid responders were found, but a slight IOP rising effect of steroids was noted during and immediately after the treatment period, in accordance with previous information. ${ }^{6}$

In conclusion, dexamethasone and diclofenac were equally effective in the treatment of postoperative inflammation in otherwise normal eyes after phacoemulsification and HSM IOL implantation. Both substances were more effective than placebo. The results support and extend the knowledge obtained from other studies, ${ }^{15}{ }^{16}$ and indicate that topical antiinflammatory treatment is generally warranted after modern cataract surgery in order to alleviate the inflammatory response and the possible risk for complications such as corneal damage and cystoid macular oedema.

\section{ACKNOWLEDGEMENTS}

We wish to thank Alcon and Leiras for providing the dexamethasone phosphate $0.1 \%$ and diclofenac sodium $0.1 \%$ solutions, and the pharmacy at St Göran's Hospital, Stockholm, for providing masked bottles containing the three study solutions.

The authors have no proprietary interest in any of the products or equipment mentioned in this article.

\section{Authors' affiliations}

C-G Laurell, C Zetterström, Karolinska Institute, St Erik's Eye Hospital, Stockholm, Sweden

\section{REFERENCES}

1 Oshika T, Yoshimura K, Miyata N. Postsurgical inflammation after phacoemulsification and extracapsular extraction with soft or conventional intraocular lens implantation. J Cataract Refract Surg 1992; 18:356-61

2 Laurell CG, Zetterström C, Philipson B, et al. Randomized study of the blood-aqueous barrier reaction after phacoemulsification and extracapsular cataract extraction. Acta Ophthalmol Scand 1998;76:573-8.

3 Pande MV, Spalton DJ, Kerr-Muir MG, et al. Postoperative inflammatory response to phacoemulsification and extracapsular cataract surgery: aqueous flare and cells. J Cataract Refract Surg 1996;22(suppl):770-4

4 Laurell CG, Wickström K, Zetterström C, et al. Inflammatory response after endocapsular phacoemulsification or conventional extracapsular lens extraction in rabbit eyes. Acta Ophthalmol Scand 1997;75:401-4.

5 Ygge J, Wenzel M, Philipson B, et al. Cellular reactions on heparin surface-modified versus regular PMMA lenses during the first postoperative month: a double masked and randomized study using specular microphotography. Ophthalmology 1990;97:1216-24. 
6 Havener WH. Corticosteroid therapy. In: Ocular pharmacology. 3rd ed. St Louis: CV Mosby, 1974;343-95.

7 Kraff MC, Sanders DR, McGuigan L, et al. Inhibition of blood-aqueous barrier breakdown with diclofenac. A fluorophotometric study. Arch Ophthalmol 1990;108:380-3.

8 Onodera T, Gimbel HV, DeBroff BM. Effects of cycloplegia and iris pigmentation on postoperative intraocular inflammation. Ophthalmic Surg 1993;24:746-52.

9 Drolsum L, Davanger M, Haaskjold E. Risk factors for an inflammatory response after extracapsular cataract extraction and posterior chamber IOL. Acta Ophthalmol Scand 1994;72:21-6.

10 Shepherd JR. In situ fracture. J Cataract Refract Surg 1990;16:436-40.

11 Burde R, Waltman SR. Topical corticosteroids after cataract surgery. Ann Ophthalmol 1972;4:290-3.

12 Nishi O, Nishi K, Imanishi M. Synthesis of interleukin-1 and prostaglandin E2 by lens epithelial cells of human cataracts. $\mathrm{Br} J$ Ophthalmol 1992;76:338-41.

13 Nishi O, Nishi K. Disruption of the blood-aqueous barrier by residual lens epithelial cells after intraocular lens implantation. Ophthalmic Surg 1992;23:325-9.
14 Wenzel M, Dahlke C, Tahmaz E, et al. Zur Bedeutung der Kortikosteroide in der Nachsorge von Patienten nach Kataraktextraktion und Linsenimplantation. Klin Mbl Augenheilk 1992;200:262-6.

15 Chang DF, Garcia IH, Hunkeler JD, et al. Phase II results of an intraocular steroid delivery system for cataract surgery. Ophthalmology 1999: 106:1 172-7.

16 Holzer MP, Solomon KD, Sandoval HP, et al. Comparison of ketorolac tromethamine $0.5 \%$ and loteprednol etabonate $0.5 \%$ for inflammation after phacoemulsification: prospective randomized double-masked study. J Cataract Refract Surg 2002;28:93-9.

17 Ku EC, Signor C, Eakins KE. Antiinflammatory agents and inhibition of ocular prostaglandin synthetase. Adv Prostaglandin Tromboxane Leukotriene Res 1976;2:819-23.

18 Scholer DW, Ku EC. Pharmacology of diclofenac sodium. Am J Med 1986;80(Suppl 4B):34-8.

19 Wolter JR, Cytopathology of of intraocular lens implantation. Ophthalmology 1985;92:135-42.

20 Wallentin N, Lundgren B, Lundberg C. Lack of correlation between intraocular inflammation and after-cataract formation in the rabbit eye. $J$ Cataract Refract Surg 2000;26: 1389-97.

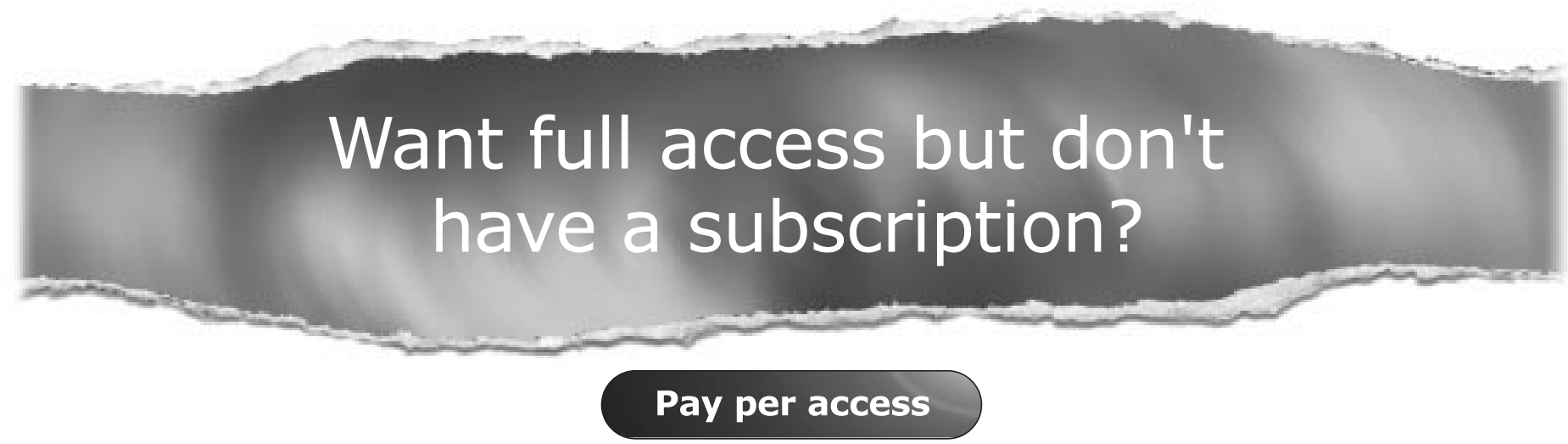

For just US $\$ 25$ you can have instant access to the whole website for 30 days. During this time you will be able to access the full text for all issues (including supplements) available. You will also be able to download and print any relevant pdf files for personal use, and take advantage of all the special features British Journal of Ophthalmology online has to offer.

\section{www.bjophthalmol.com}

